\title{
Pre-extension Demonstration and Evaluation of Bread Wheat Varieties in Metta and Jarso Districts of East Hararghe Zone
}

\author{
Abdulaziz Teha \\ Oromia Agricultural Research Institute, Fedis Agricultural Research Center, \\ P.O. Box 904, Harar, Ethiopia
}

\begin{abstract}
The study was focused on demonstration of bread wheat technologies major wheat growing area in east Hararghe .The objectives were to evaluate and demonstrate improved bread wheat variety with their production package to the farmers and assess farmers' feedback towards improved bread wheat technology. The activity was conducted in main cropping season 2019-2020 for two year at Jarso and Metta districts. A total of fourty (40) trial farmers were selected from two potential bread wheat growing Districts (Jarso and Metta). Four FRG having 60 farmers were established. Two improved bread wheat varieties along with local check (Senate, Liban and Local) were planted on the plot of $10 \mathrm{mx} 10 \mathrm{~m}$ per trial farmers. Yield data, economic data, farmers' perception and preferences were collected and yield data were analyzed by using ANOVA. The results of ANOVA showed that yield of improved bread wheat showed statistically significant at $0.01 \%$ the probability level of between improved and local treatments. The yield performance of the improved varieties (Senate,Liban and local) were 36.83, 30.27 and $25.47 \mathrm{qt} / \mathrm{ha}$ at Afgug and 39.14,33.23 and $28.35 \mathrm{qt} / \mathrm{ha}$ at Dursitu Bilsuma respectively. Farmer preference of improved \& local variety with improved management ranks Sennate $1^{\text {st }}$ and Liban $2^{\text {nd }}$ at both Jarso and Metta respectively. Generally, sennate with recommended package showed higher yield advantage than liban and local. Therefore senate variety it is recommended for further scaling up.
\end{abstract}

Keywords: Bread Wheat, Demonstration, Senate, Liban,Metta and Jarso

DOI: $10.7176 / \mathrm{FSQM} / 112-04$

Publication date: January $31^{\text {st }} 2022$

\section{Introduction}

Bread wheat (Triticum aestivum L.) is mainly cultivated by small scale farmers in Ethiopia. It ranks fourth in area coverage next to teff, maize and sorghum, respectively. It is the main staple food for about $36 \%$ of the Ethiopian population (Bishaw, Z., 2011). Arsi and Bale highlands are the major wheat producing regions of Ethiopia and are deemed to be the wheat belts of East Africa. The area under wheat production is estimated to be about 1.6 million hectares, which makes the country the largest wheat producer in sub-Saharan Africa (Bishaw, Z., 2011).

Wheat is an important staple food crop in Ethiopia, especially in urban areas. It is a staple food in the diets of several Ethiopian, providing about 15 percent of the caloric intake for the country's over 90 million population (FAO 2015a). It accounts close to 17 percent of acreage of arable land and a fifth of all cereal food crops produced in the country in 2013/14 (CSA, 2013/14a). After South Africa, Ethiopia is the second largest wheat producer in sub-Saharan Africa (FAO 2015b).Despite substantial increases in wheat area, 33\% of the national demand is fulfilled by imports and food aids. The national average wheat yield of 1.8 tones ha-1 is below Sub-Saharan Africa and world averages (Dixon et al., 2009). There are several biophysical and socio-economic constraints affecting wheat production and productivity in the country. The national agricultural research system has developed diverse improved bread wheat varieties with key attributes such as high grain yield and quality, resistance to rusts, tolerance to drought and consumer preferences (taste, baking and nutritional quality). Farmers however have subjective preferences for different varietal attributes and their varietal demand is significantly affected by their perceptions (Bishaw et al., 2011). Thus, this proposal initiated to demonstrate and promotes improved bread wheat varieties in the study areas.

\section{Objectives}

To evaluate the yield performance of bread wheat varieties under farmers' condition

To create awareness on the importance of Bread wheat technology

To develop knowledge and skill of farmers and other stalk holders have on bread wheat varieties

To strengthen the institutional and other stallholders linkage on agricultural research output

To collect farmers' feedback on demonstrated bread wheat varieties

\section{Materials and Methods}

Description of the Study Area

Jarso is bordered on the south by the Harari Region, on the west by Kombolcha, on the north by the city of Dire Dawa, on the east by the Somali Region, and on the southeast byGursum. The administrative center of this woreda is Ejersa Goro. The altitude of this woreda ranges from 1050 to 3030 meters above sea level;Mountain Gara Sirirta, 
Aybera, Kilisa and Bekekalu are amongst the highest peaks. Rivers include the Gideya. A survey of the land in Jarso (reported in 1995/96) shows that $19.3 \%$ is arable or cultivable, $1.7 \%$ pasture, $21.6 \%$ forest, and the remaining $57.4 \%$ is considered degraded or otherwise unusable. Khat, fruits and vegetables are important cash crops.

Meta woreda is located in East Hararghe zone of Oromia region. Meta is bordered to the southwest by Deder woreda, to the northwest by Goro Gutu woreda, to the north by the Somali regional state, to the northeast by Kersa woreda, and to the southeast by Bedeno woreda. The administrative capital of the Woreda is Chelenko. The Woreda is characterized by valleys in pocket areas, and rugged topography with many hills. There are some permanent rivers in the Woreda. Notable among these is the river that supplies water to the town of Chelenko. Besides, there are many perennial springs originating from below the mountains and crossing the valleys. One lake is also found. Groundwater resources are always there. Mixed crop production and livestock rearing characterize the farming system of the Woreda. The major crops produced in the Woreda include sorghum, maize, wheat, and haricot bean, vegetables of different kinds and fruit trees. Although there is no meteorological station for recording rainfall, the rainfall pattern in the Woreda is bimodal.

\section{Site and farmers selection}

Jarso and Metta districts were selected purposively based on the potentiality, appropriateness of the area by considering lodging, slop land scape and accessibility, suit for repeatable monitoring and evaluation. Thus Afgug from Jarso and Dursitu Bilisuma from Metta were selected and one FTC from each kebele was also selected as demonstration site to reach other farmers who visit the FTC. Farmers were selected by studying their profile with the participation of Development Agents and community leaders. The selection was done purposively based on farmers' interest, land provision for this activity, interest in cost-sharing and willingness to share experiences for other farmers. The selected farmers were grouped in a form of Farmers Research Group (FRG) with the member of 15 farmers per kebeles in consideration of gender issues (women, men and youth). .Within one FRG 10 members were trial farmers ( 6 male trial farmers and 4 female trial farmers) and the rest 5 farmer work with trial farmers. Four FRGs (2FRG/ kebele) from one 15 farmers and a total of 60 farmers were organized at Jarso and Metta. Table 1: Summary of selected site and farmers with area coverage of the experiment

\begin{tabular}{lllll}
\hline District & PAs & $\begin{array}{l}\text { No. of } \\
\text { farmers }\end{array}$ & FTCs & Area covered \\
\hline Jarso & Afgug & 20 & 1 & $10 \mathrm{mx}$ 10m for each plots \\
Metta & D/Bilisuma & 20 & 1 & \\
& Total & 40 & 2 & \\
\hline
\end{tabular}

\section{Research design}

Two improved varieties and one local check were used. Senate, Liban \& local varieties were planted side by side with equal plot size. Senate and Liban varieties with local check were used as treatments. The trial farmers were used as replications. Each variety planted at the Plot Size: $10 \mathrm{mx} 10 \mathrm{~m}$, Seeding rate $150 \mathrm{~kg} / \mathrm{ha}$, Spacing $25 \mathrm{~cm}$ (Between row), Fertilizer rate: NPS/Urea $100 \mathrm{~kg} / \mathrm{ha}$

\section{Technology evaluation and demonstration methods/technique}

The evaluation and demonstration of the trials were conducted on farmers' fields to create awareness about the bread wheat varieties. The evaluation and demonstration trials followed process demonstration approach by involving FRGs, development agents and experts at different growth stage of the crop. The activity was jointly monitored by FRGs, researchers, experts and development agents.

\section{Data Collection}

Both quantitative and qualitative data were collected through personal field observation, individual interview, Focus Group Discussion by using checklist and data sheet tools. Types of collected quantitative data were number of farmers participated in FRG, yield performance, economic analysis and number of stakeholders participated on the training. While qualitative data were farmers' Knowledge/ perceptions towards the new technology and ranked using Matrix ranking.

\section{Data analysis}

Quantitative data was summarized using simple descriptive statistics (mean, frequency and percentage) while the qualitative data collected using group discussion and field observation and oral histories was analyzed using narrative explanation and argument. Finally, data from different sources were triangulated to get reliable information. 


\section{Results and Discussion}

\section{Training of farmers and other stalk holders}

Training was organized to participating farmers before commencing the trial Multidisciplinary researchers ; crop, extension and socio-economic discipline and other stakeholders (Offices of Agriculture and Natural Resource) actively participated by sharing their experience and knowledge about bread wheat production, management, postharvest handling and marketing and journalists for the sake of publicity of the work done.

Table 2: Type of profession and number of participants on the training at Afgug and D/Bilisuma

\begin{tabular}{|c|c|c|c|c|c|c|}
\hline \multirow[b]{2}{*}{ No. } & \multirow[b]{2}{*}{ Participants } & \multicolumn{2}{|c|}{ Afgug } & \multicolumn{2}{|c|}{ D/Bilisuma } & \multirow[b]{2}{*}{ Total } \\
\hline & & Male & Female & Male & Female & \\
\hline 1 & Farmers & 30 & 12 & 33 & 15 & 90 \\
\hline 2 & DAs & 12 & 3 & 10 & 3 & 28 \\
\hline 3 & District expert & 4 & 1 & 6 & 0 & 11 \\
\hline & Total & 46 & 16 & 49 & 18 & 129 \\
\hline
\end{tabular}

Among the training participant stakeholders, $69.8 \%$ were farmers. From those farmers, 30\% are female farmers. During the training 35 leaflets and 20 small manuals on the technology that are organized in Afaan Oromoo and English languages were distributed. More over different questions, opinions and suggestions were raised and reacted from the concerned bodies. Most farmers showed high interest towards improved bread wheat technology production because of better yield and earned income by selling it for different stakeholders (neighbors' farmers and Non-Government Organizations). Generally, all farmers were very interested to have the technology for their future production. Therefore, all concerned bodies were shared their responsibility for the future intervention and wider reach out of the technology.

\section{Agronomic and yield performance}

The following table describes the yield performances of the demonstrated bread wheat varieties across the study site. The yield performance of the improved varieties (Sennate, Liban and local) were 36.83, 30.27 and 25.47 qt/ha at Afgug, 39.14, 33.23 and $28.35 \mathrm{qt} / \mathrm{ha}$ at Dursitu Bilisuma respectively. The average yield performance of Sennate and liban were higher than local variety at both location but statistically no significant difference between two improved varieties across the locations was observed.

Table 3.Yield performance of improved Bread wheat varieties across districts on Farmers land

\begin{tabular}{lllllll}
\hline PA & Varieties & N & Std. Deviation & Mean (qt/ha) & Maximum & Minimum \\
\hline Afgug & Senate & 20 & 1.94 & 36.83 & 39.40 & 31.50 \\
& Liban & 20 & .58 & 30.27 & 31.10 & 29.50 \\
& Local & 20 & .59 & 25.47 & 26.30 & 24.70 \\
\hline \multirow{2}{*}{ Bishan Bahe } & Senate & 20 & 1.25 & 39.14 & 40.30 & 37.30 \\
& Liban & 20 & 3.44 & 33.23 & 39.10 & 29.00 \\
& Local & 20 & 2.39 & 28.35 & 33.50 & 24.00 \\
\hline & Total & 5.13 & 32.22 & 40.30 & 24.00 \\
\hline
\end{tabular}

Table 4: ANOVA

\begin{tabular}{|c|c|c|c|c|c|}
\hline & Sum of Squares & df & Mean Square & $\mathbf{F}$ & Sig. \\
\hline \multirow{2}{*}{$\begin{array}{l}\text { Between Groups } \\
\text { Within Groups }\end{array}$} & 2465.99 & 2 & 1232.99 & 214.37 & .00 \\
\hline & 672.92 & 117 & 5.75 & & \\
\hline Total & 3138.92 & 119 & & & \\
\hline
\end{tabular}

\section{Yield Advantage}

The result indicated that Senate and liban varies have better yield (37.99 qt/ha) and (31.75 qt/ha) when compared with local check.

Yield advantage of the demonstrated varieties was calculated using the following formula.

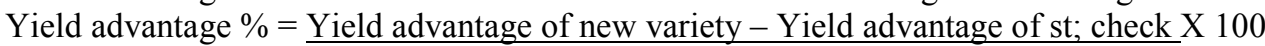

Yield advantage of standard check 
Table 5: Summary of yield performance in study areas

\begin{tabular}{|c|c|c|c|}
\hline Varieties & Average yield qt/ha & $\begin{array}{l}\text { Yield difference } \\
\mathrm{qt} / \mathrm{ha}\end{array}$ & $\begin{array}{l}\text { Yield advantage over the local check } \\
(\%)\end{array}$ \\
\hline Senate & 37.99 & 11.01 & 41.17 \\
\hline Liban & 31.75 & 4.84 & 17.98 \\
\hline Local & 26.91 & & \\
\hline
\end{tabular}

\section{Economic Analysis of bread wheat production}

The followed table describes the financial costs and returns of the improved bread wheat varieties across two demonstration sites for 2019/2020 production year the calculation used 4000 birr as farm gate price for a quintal of bread wheat grain. Thus the profit per hectare gained from Sennate variety were 126,902 and 136,142 ETB at afgug and dursitu bilisuma kebeles respectively. Whereas liban profit were at 100,662 and 112,502ETB at afgug and dursitu bilisuma kebeles

Table 6: Financial analysis for Bread Wheat varieties across the districts

\begin{tabular}{|c|c|c|c|c|c|c|c|}
\hline \multicolumn{8}{|l|}{ Financial analysis } \\
\hline \multicolumn{4}{|l|}{ Location: Jarso(Afgug) } & \multicolumn{4}{|c|}{ Location: Metta(Dursitu Bilisuma) } \\
\hline \multirow[t]{2}{*}{ Parameters } & \multicolumn{2}{|l|}{ Varieties } & \multirow[b]{2}{*}{ Local } & \multirow[t]{2}{*}{ Parameters } & \multicolumn{3}{|c|}{ Varieties } \\
\hline & Sennate & Liban & & & Sennate & Liban & Local \\
\hline Yield qt/ha(Y) & 36.83 & 30.27 & 25.47 & Yield qt/ha(Y) & 39.14 & 33.23 & 28.35 \\
\hline Price $(\mathrm{P})$ per quintal & 4000 & 4000 & 4000 & $\begin{array}{l}\text { Price }(\mathrm{P}) \quad \text { per } \\
\text { quintal }\end{array}$ & 4000 & 4000 & 4000 \\
\hline $\begin{array}{l}\text { Total } \\
(\mathrm{TR})=\mathrm{TR}=\mathrm{Y} * \mathrm{P}\end{array}$ & 147,320 & 121,080 & 101,880 & $\begin{array}{l}\text { Total Revenue } \\
(\mathrm{TR})=\mathrm{TR}=\mathrm{Y} * \mathrm{P}\end{array}$ & 156,560 & 132,920 & 113,400 \\
\hline Variable costs & & & & Variable costs & & & \\
\hline Seed cost & 6000 & 6000 & 6000 & Seed cost & 6000 & 6000 & 6000 \\
\hline Fertilizer cost & 1,418 & 1,418 & 1,418 & Fertilizer cost & 1,418 & 1,418 & 1,418 \\
\hline Labor cost & 7,000 & 7,000 & 7,000 & Labor cost & 7,000 & 7,000 & 7,000 \\
\hline $\begin{array}{ll}\text { Total } & \text { Variable } \\
\text { costs(TVC) } & \\
\end{array}$ & 14,418 & 14,418 & 14,418 & $\begin{array}{l}\text { Total Variable } \\
\text { costs(TVC) }\end{array}$ & 14,418 & 14,418 & 14,418 \\
\hline Fixed costs & & & & Fixed costs & & & \\
\hline Cost of land & 6,000 & 6,000 & 6,000 & Cost of land & 6,000 & 6,000 & 6,000 \\
\hline Total fixed costs (TFC) & 6,000 & 6,000 & 6,000 & $\begin{array}{l}\text { Total fixed } \\
\text { costs (TFC) }\end{array}$ & 6,000 & 6,000 & 6,000 \\
\hline $\begin{array}{l}\text { Total cost } \\
(\mathrm{TC})=\mathrm{TVC}+\mathrm{TFC}\end{array}$ & 20,418 & 20,418 & 20,418 & $\begin{array}{l}\text { Total cost }(\mathrm{TC}) \\
=\mathrm{TVC}+\mathrm{TFC}\end{array}$ & 20,418 & 20,418 & 20,418 \\
\hline $\begin{array}{l}\text { Gross Margin }(\mathrm{GM})= \\
\text { TR - TVC }\end{array}$ & 132,902 & 106,662 & 87,462 & $\begin{array}{l}\text { Gross Margin } \\
\text { (GM) = TR - } \\
\text { TVC }\end{array}$ & 142,142 & 118,502 & 98,982 \\
\hline Profit $=$ GM-TFC & 126,902 & 100,662 & 81,462 & $\begin{array}{l}\text { Profit=GM- } \\
\text { TFC }\end{array}$ & 136,142 & 112,502 & 92,982 \\
\hline
\end{tabular}

\section{Results of Knowledge Test}

A simple knowledge test items were developed based on the contents of training and production package practices and knowledge level of participant farmers regarding improved bread wheat production technologies was measured before and after implementation. Score of 1 is given for correct answers and 0 for incorrect answers. As one can observe from the table 7 below, the percentage of respondents for correct answers is increased after intervention. As a result, the percentage of respondents for incorrect answers is decreased. 
Table 7.Percentage of Respondents for each knowledge Items

\begin{tabular}{|c|c|c|c|c|c|}
\hline \multirow{3}{*}{ No } & \multirow{3}{*}{ Knowledge Items } & \multicolumn{4}{|c|}{ Respondent Percentage } \\
\hline & & \multicolumn{2}{|c|}{ Before } & \multicolumn{2}{|c|}{ After } \\
\hline & & Correct & Incorrect & Correct & Incorrect \\
\hline 1 & The Name of improved Variety Wheat used & 53.3 & 46.7 & 66.7 & 33.3 \\
\hline 2 & Ploughing frequency & 63.3 & 36.7 & 70 & 30 \\
\hline 3 & $\begin{array}{l}\text { The recommended seeding rate of improved } \\
\text { bread wheat }\end{array}$ & 36.7 & 63.3 & 53.3 & 46.7 \\
\hline 4 & The Maturity date of Bread wheat & 43.3 & 56.7 & 46.3 & 53.3 \\
\hline 5 & The symptom of disease that affect bread wheat & 50 & 50 & 56.7 & 43.3 \\
\hline 6 & The disease tolerant varieties & 53.3 & 46.7 & 73.3 & 26.7 \\
\hline 7 & The chemicals used for bread wheat disease & 50 & 50 & 50 & 50 \\
\hline 8 & The season that wheat disease severely occurred & 30 & 70 & 43.3 & 56.7 \\
\hline 9 & Yield per hectare of improved bread wheat & 40 & 60 & 71 & 29 \\
\hline 10 & Market price of bread wheat & 66.7 & 33.3 & 66.7 & 33.3 \\
\hline 11 & Exact Source of improved bread wheat & 43.3 & 56.7 & 56.7 & 43.3 \\
\hline
\end{tabular}

Source: from own computed data (2021)

The mean score for knowledge test before intervention and after intervention is 5.3 and 6.4 respectively. The result of paired-sample t-test indicates a significant difference between the mean score for knowledge test before intervention and after intervention at 1\% significant level. This implies an improvement of farmers' knowledge regarding the improved bread wheat technologies due to technological intervention.

Table 8. Results of paired-sample t-test for knowledge test

\begin{tabular}{|l|l|l|l|}
\hline & Mean & St.Dev & t-value \\
\hline Total score before & 5.3 & 1.36 & 6.44 \\
\hline Total score After & 6.4 & 1.37 & \\
\hline
\end{tabular}

Note: $* * *$ : refers to significance at $1 \%$ level, respectively

Source: computed from own data (2021)

\section{Farmers' Opinion/Perception}

Farmers' in the study area selected the best performing improved bread wheat varieties by using their own criteria. The opinion of those farmers on varietal preference was collected from participants during variety demonstration. The major criteria used by farmers were tillering capacity, seed per spicke disease tolerant, plant height, early maturing, yield, seed quality and uniformity. Therefore, most farmers selected senate variety to reuse on their farm for the future. The following table describes farmers' selection criteria and their perception (feedback) toward the varieties

Table.9 Ranks of the varieties based on farmers' selection criteria

\begin{tabular}{ll|l}
\hline Varieties & \multicolumn{1}{c}{$\begin{array}{l}\text { Farmers } \\
\text { rank }\end{array}$} & \multicolumn{1}{l}{ Reasons } \\
\hline Senate & $1^{\text {st }}$ & $\begin{array}{l}\text { High tillering capacity, seed per spike medium disease tolerant, high plant height, } \\
\text { early maturing, high yield, good seed quality, uniform }\end{array}$ \\
Liban & $2^{\text {nd }}$ & $\begin{array}{l}\text { High tillering capacity, seed per spike medium disease tolerant, good plant height, } \\
\text { early maturing, good yield, medium seed quality, uniform }\end{array}$ \\
Local & $3^{\text {rd }}$ & $\begin{array}{l}\text { low tillering capacity, seed per spike medium disease tolerant, low plant height, } \\
\text { early maturing, low yield, low seed quality, not uniform }\end{array}$ \\
\hline
\end{tabular}

\section{Conclusion and Recommendation}

The result showed yield of improved varieties statistically significant difference over the local check. Field day was organized and farmers visit the demonstration plots and select the best varieties based on their own listed criteria.In general, tillering capacity, seed per spike, disease tolerant, plant height, early maturing, yield, seed size and uniformity. The overall harvested mean yield of senate, liban and local was $37.98 \mathrm{qt} / \mathrm{ha}, 31.75$ and $26.91 \mathrm{qt} / \mathrm{ha}$ respectively. Agronomic data result shows that senate and liban varieties were selected as compared to the standard local check variety. Senate and Liban were farmers' $1^{\text {st }}$ and $2^{\text {nd }}$ preferred bread wheat varieties respectively in Jarso and Metta districts. Therefore, since senate has been preferred by farmers and gave good grain yield. Senate improved bread wheat variety should be promoted to a wider scale at Jarso and Metta districts for pre-scaling up. Effective and efficient delivery of technical advices and support to farmers is highly required to improve wheat 
production and productivity help us in making our research demand-driven and enhance wheat production and productivity.

\section{References}

Bishaw, Z., Struik, P.C., van Gastel, A.J.G., 2011. Wheat and barley seed system in Syria: Farmers'varietal perception, seed sources and seed management. Int. J. Plant Prod. 5 (4), 323-347.

Dixon, J., Braun, H.J., Kosina, P., Crouch, J., 2009. Wheat Facts and Futures 2009. Mexico, D.F.: CIMMYT.

CSA (Central Statistical Agency). 2011. Large and Medium Scale Commercial Farms Sample Survey. Statistical Report on Area and Production of Crops, and Farm Management Practices. Statistical Bulletin 505. Addis Ababa, Ethiopia.

FAO (Food and Agriculture Organization) (2015a). Food Balance Sheets. FAOSTAT. Rome.

FAO (Food and Agriculture Organization) (2015b). Agricultural Production Statistics. FAOSTAT. Rome.

CSA (Central Statistical Agency) (2014b). Agricultural Sample Survey 2013/14. Volume I: Report on:Land Utilisation. Addis Ababa. 